\title{
Modified biovectors for the tuneable activation of anti-platelet carbon monoxide release $\dagger$
}

\author{
Lucas Prieto, ${ }^{a}$ Jeremie Rossier, ${ }^{c}$ Katarzyna Derszniak, ${ }^{b}$ Jakub Dybas, ${ }^{b}$ \\ René M. Oetterli, ${ }^{a}$ Emmanuel Kottelat, ${ }^{,}$Stefan Chlopicki, ${ }^{\text {bd }}$ Felix Zelder (ID *a and \\ Fabio Zobi (D) *c
}

\begin{abstract}
This communication describes the anti-platelet effects of a new class of cis-rhenium(II)-dicarbonyl-vitamin $B_{12}$ complexes ( $B_{12}$-ReCORMs) with tuneable $\mathrm{CO}$ releasing properties.
\end{abstract}

Carbon-monoxide releasing molecules (CORMs) represent an innovative class of compounds which attract interest due to their potential therapeutic utility. Unlike most common drugs whose pharmacological action is dependent on their interaction with a macromolecular target and whose potency is dictated by the stability of the drug-target complex, CORMs exert their therapeutic action via the liberated CO molecules. ${ }^{1-5}$ However, apart from the common scientific consensus that CORM-based therapy should not lead to significant carboxyhemoglobin $(\mathrm{COHb})$ formation and to the inhibition of respiratory enzymes that are sensitive to $\mathrm{CO}$, it is questionable whether CORMs should release CO slowly or rapidly and what kinetics of $\mathrm{CO}$ release is most advantageous for therapeutic applications. There are only few reports clearly showing the advantages of CORMs slowly releasing CO over those releasing CO instantly ${ }^{6,7}$ and they relate to the anti-platelet effects of CORMs. Furthermore, it has proved chemically challenging to fine-tune the activation and the rate of $\mathrm{CO}$ release within a family of structurally similar CORM compounds. For all of these reasons, versatile classes of CORMs with tuneable release properties affording anti-platelet activity are highly desired for tackling these open questions in systematic structure-activity relationship studies. Such studies will facilitate the development of CORMs with optimal antiplatelet activity. ${ }^{6-8}$

\footnotetext{
${ }^{a}$ University of Zurich, Department of Chemistry, Winterthurerstrasse 190,

CH-8057 Zurich, Switzerland. E-mail: felix.zelder@chem.uzh.ch;

Web: www.felix-zelder.net; Fax: +41446356803

${ }^{b}$ Jagiellonian Centre for Experimental Therapeutics (JCET), Jagiellonian University, Krakow, Poland

${ }^{c}$ Department of Chemistry, University of Fribourg, Chemin du Musée 9,

1700 Fribourg, Switzerland. E-mail: fabio.zobi@unifr.ch

${ }^{d}$ Chair of Pharmacology, Jagiellonian University Medical College, Krakow, Poland.

E-mail: stefan.chlopicki@jcet.eu

$\dagger$ Electronic supplementary information (ESI) available. See DOI: 10.1039/c7cc03642f
}

Inspired by our groups' efforts to develop (a) versatile CORMs for biomedical applications ${ }^{9-12}$ and (b) vitamin $\mathrm{B}_{12}$ derivatives with tuneable coordination and redox properties, ${ }^{13-15}$ we envisaged to design and study cis-rhenium(II)-dicarbonyl-vitamin $\mathrm{B}_{12}$ complexes with adjustable CO releasing properties (Scheme 1) within the range for kinetics of CO release of CORM A1 (Scheme 2a). ${ }^{16}$ This molecule exhibits strong anti-platelet and anti-thrombotic activities without a hypotensive effect. ${ }^{6,7}$ In particular, for the present prodrug strategy, we started from prototype $\mathrm{B}_{12}-\mathrm{ReCORM}-2^{10}$ (compound 8 in the present study) in which the CORM cis-[Re(CO $\left.{ }_{2} \mathrm{Br}_{4}\right]^{2-}(\mathbf{1})$ is attached to the axial cyano group of vitamin $\mathrm{B}_{12}$. We speculated whether modifications of the $\mathrm{Co}^{\mathrm{III}} / \mathrm{Co}^{\mathrm{I}}$ redox properties of the $\mathrm{B}_{12}$ ligand would translate into control of the CO-releasing properties at the opposite $\mathrm{Re}^{\mathrm{II}}-(\mathrm{CO})_{2}$ fragment.

This approach seemed to be reasonable because small variations in the coordination sphere of rhenium complexes have profound consequences on the electrochemistry, water stability and $\mathrm{CO}$ releasing properties of the dicarbonyl core. ${ }^{17} \mathrm{~B}_{12}$ appeared to be attractive as ligand for the rhenium-based CORM entity mainly because of two reasons: (a) its cellular uptake properties can be exploited to deliver therapeutic agents specifically at disease sites; ${ }^{18-20}(\mathrm{~b})$ the electronic properties at the cobalt center can be selectively modified by introducing structural modifications at the corrin- $\pi$-system..$^{21-24}$

Having the general design of the $\mathrm{B}_{12}$-ReCORMs derivatives in mind (Scheme 1), we synthesized and studied first a series of

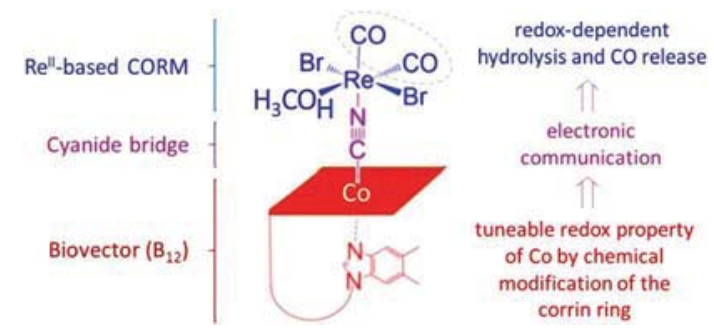

Scheme 1 General design concept for the tuneable activation of CORMbiovectors conjugates. 
C: CORM-biovectors

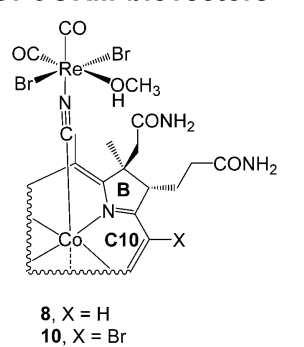

$3, \mathrm{X}=\mathrm{Br}$
$4, \mathrm{X}=\mathrm{Cl}$

$\left.\underset{\text { CORM A1 }}{2 \mathrm{Na}^{+}\left[\mathrm{H}_{3} \mathrm{~B}-\mathrm{O}_{0}\right.}\right]^{2-}$

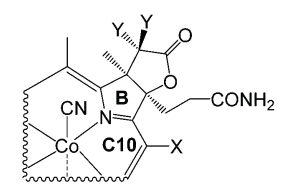

2, $\mathrm{X}=\mathrm{H} / \mathrm{Y}=\mathrm{H}$

$5, X=\mathrm{Cl} / \mathrm{Y}=\mathrm{H}$

6, $X=\mathrm{H} / \mathrm{Y}=\mathrm{Br}$
$\mathrm{7} \mathrm{X}=\mathrm{H} / \mathrm{Y}=\mathrm{C}$

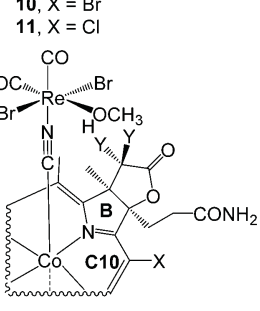

9, $\mathrm{X}=\mathrm{H} / \mathrm{Y}=\mathrm{H}$

$12, \mathrm{X}=\mathrm{Cl} / \mathrm{Y}=\mathrm{H}$

13, $\mathrm{X}=\mathrm{H} / \mathrm{Y}=\mathrm{Br}$

14, $\mathrm{X}=\mathrm{H} / \mathrm{Y}=\mathrm{Cl}$
Scheme 2 (A) Re"-Based CORM 1 and CORM A1; (B) modified $B_{12}{ }^{-}$ biovectors 2-7; (C) CORM- $\mathrm{B}_{12}$ complexes 8-14.

Table 1 Electrochemical and spectroscopic data of vitamin $B_{12}$, its derivatives (2-7)

Compound $E_{\text {red }}{ }^{a}(\mathrm{mV}) \gamma$ band, nm $(\log \varepsilon) \beta / \alpha\left(\pi-\pi^{*}\right)$ bands, nm $(\log \varepsilon)$

\begin{tabular}{llll}
\hline $\mathbf{B}_{12}$ & -1010 & $361(4.4)$ & $519(3.9) / 550(3.9)$
\end{tabular}

$2 \quad-929 \quad 359(4.3) \quad 523(3.7) / 551(3.7)$

$\begin{array}{llll}3 & -798 & 365(4.3) & 550(3.7) / 576(3.7)\end{array}$

$4 \quad-810 \quad 364(4.2) \quad 551(3.6) / 574(3.7)$

$5 \quad-784 \quad 363(4.6) \quad 551(3.6) / 577(3.6)$

$6 \quad-710 \quad 363(4.2) \quad 531(3.7) / 559(3.7)$

$7 \quad-715 \quad 363(4.2) \quad 531(3.7) / 554(3.7)$

${ }^{a} E_{\text {red }}$ data refer to $\mathrm{Co}^{\mathrm{III}} \rightarrow \mathrm{Co}^{\mathrm{I}}$ reduction (in $0.1 \mathrm{M}$ Tris buffer at $\mathrm{pH}$ 8).

six cobalamins for coordinating them later to 1 (Scheme 2A). In particular, the cobalamin ligands contain structural modifications at $\mathrm{C} 10$ and/or at the B ring of the corrin macrocycle (Scheme 2B) and were synthesized according to literature procedures or modifications thereof (see ESI $\dagger$ ). ${ }^{25-28}$ We examined the electronic properties of compounds 2-7 (Table 1) by spectroscopic (UV-vis) and electrochemical means (cyclovoltammetry). As a general trend, we observed an increase in $E_{\text {red }}\left(\mathrm{Co}^{\mathrm{III}} / \mathrm{Co}^{\mathrm{I}}\right)$ (cathodic reduction potential for the $\mathrm{Co}^{\mathrm{III}}$ to $\mathrm{Co}^{\mathrm{I}}$ transition) when electronic withdrawing groups $(\mathrm{Br}$ or $\mathrm{Cl})$ and/or a $c$-lactone moiety at the B-ring were introduced in the cobalamin structure. For example, $E_{\text {red }}\left(\mathrm{Co}^{\mathrm{III}} / \mathrm{Co}^{\mathrm{I}}\right)$ was increased by $212 \mathrm{mV}$ compared to $\mathrm{B}_{12}$ when one $\mathrm{Br}$ is introduced at $\mathrm{C} 10$ (3) and this effect was further enhanced by $88 \mathrm{mV}$ when an additional dibromolactone moiety was attached to the periphery of the $\mathrm{B}$ ring (6).

Having demonstrated that chemical modifications of the corrin macrocycle change the overall electronic properties of the cobalamin ligands $\mathbf{2 - 7}$, these biovectors were coordinated to CORM 1 through their axial cyano group (Scheme 2). ${ }^{29}$ The formation of a Co-CN-Re bond to afford CORM-biovectors 8-14 (Scheme 2C) was achieved in one single step and was confirmed
Table 2 Half-life $\left(t_{1 / 2}\right)$ of stability of 8-14 in water and their $\mathrm{CO}$ release

\begin{tabular}{lcc}
\hline Compound $t_{1 / 2}$ hypochromic shift of $410 \mathrm{~nm}$ band $^{a}$ & $t_{1 / 2}$ of CO release \\
\hline $\mathbf{8}$ & $60.1 \pm 2.9$ & $33.6 \pm 2.3$ \\
$\mathbf{9}$ & $40.2 \pm 1.6$ & $24.5 \pm 1.8$ \\
$\mathbf{1 0}$ & $29.5 \pm 2.6$ & $25.3 \pm 1.8$ \\
$\mathbf{1 1}$ & $29.6 \pm 2.9$ & $22.6 \pm 0.7$ \\
$\mathbf{1 2}$ & $27.3 \pm 1.7$ & $24.3 \pm 3.0$ \\
$\mathbf{1 3}$ & $19.1 \pm 1.4$ & $20.2 \pm 2.9$ \\
$\mathbf{1 4}$ & $24.9 \pm 2.2$ & $16.2 \pm 1.2$
\end{tabular}

${ }^{a}$ In $\mathrm{H}_{2} \mathrm{O}$ (minutes). ${ }^{b}$ Measured from the first order exponential increase of MbCO soret band.

by IR spectroscopy and inductively coupled plasma/optical emission spectrometry (ICP/OES) (see ESI $\dagger$ ). With these compounds in hand, we investigated the stability and therefore the CO releasing properties of the $\mathrm{Re}^{\mathrm{II}}$-based CORM within the CORM-biovector scaffolds (8-14) by UV-vis kinetic experiments. The main difference in the spectra of the biovectors (Scheme $2 \mathrm{~B}$, 2-7) and the CORM-biovectors (Scheme 2C, 8-14) is the presence of a band at $c a .410 \mathrm{~nm}$ for the latter compounds. This band is hypsochromically shifted when the bromide ions of the $\mathrm{Re}^{\mathrm{II}}$ complex undergo aquation. This ligand exchange is the first step towards the aerobic degradation of the $\mathrm{Re}^{\mathrm{II}}$ core leading to CO release. ${ }^{10}$ Therefore, changes in this band in DMSO (see ESI, $\dagger$ Fig. S21) and aqueous solutions (Table 2) over time were monitored.

CORM-biovectors 8-14 show a half-life $\left(t_{1 / 2}\right)$ stability in DMSO varying from 1 to $>3$ hours (see ESI, $\dagger$ Table S1). When this experiment was performed in an aqueous solution, a first order decay behavior was observed. We were delighted to find that $t_{1 / 2}$ of aquation of the cis-[Re( $\left.(\mathrm{CO})_{2} \mathrm{Br}_{2}\right]^{0}$ core steadily decreased as $E_{\text {red }}\left(\mathrm{Co}^{\mathrm{III}} / \mathrm{Co}^{\mathrm{I}}\right)$ of the $\mathrm{B}_{12}$-biovector increased (Fig. 1), varying from $60(8)$ to $c a .20 \mathrm{~min}(13)$. The observed trend may be rationalized considering that an electron deficient $\mathrm{Co}^{\text {III }}$ ion obtains an enhanced $\sigma$-donation from the axial cyanide bridge. As a consequence, the 17-electron $\mathrm{Re}^{\mathrm{II}}$ complex receives weaker electronic stabilization from the bridging ligand, rendering it more labile towards ligand substitution. Thus, within CORM-biovectors 8-14, electronic properties of the modified biovectors appear to be the

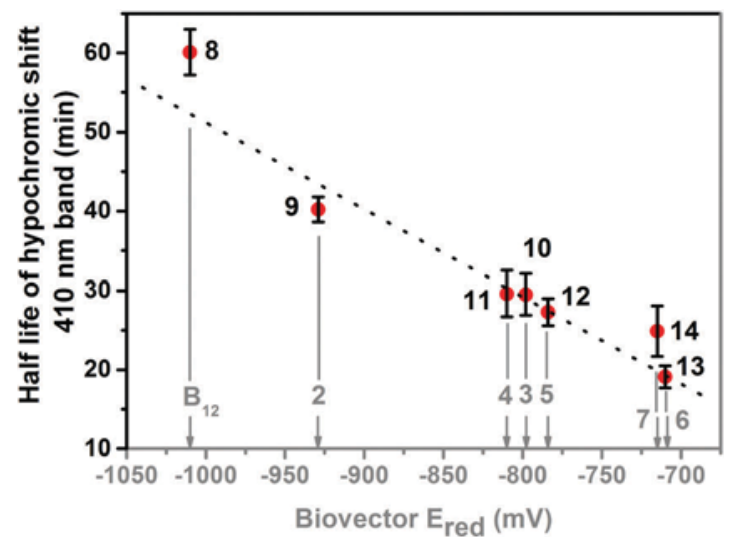

Fig. 1 Plot of $t_{1 / 2}$ (min) of hypochromic shift of $410 \mathrm{~nm}$ band of compounds 8-14 vs. $E_{\text {red }}\left(\mathrm{Co}^{\prime \prime \prime} / \mathrm{Co}^{\prime}\right)$ of the same species. 
main effect regarding the rate of aquation of the $\mathrm{Re}^{\mathrm{II}}$ based CORM. Nonetheless, a slight deviation from linearity $\left(R^{2}=93 \%\right)$ suggests that additional factors might also play a minor role.

Knowing that aquation is the prerequisite for CO release, the relative CO releasing rates of CORM-biovectors 8-14 were determined using the well-known myoglobin ( $\mathrm{Mb}$ ) assay. The apparent rate and amount of $\mathrm{CO}$ release were calculated by UV-vis spectroscopy: the formation of carboxy-myoglobin (MbCO) is monitored by an increase in the Soret band of the protein $\left(\lambda_{\max }=424 \mathrm{~nm}\right)$. Consequently, the $t_{1 / 2}$ of Soret band shift was taken as a direct measure of $t_{1 / 2}$ of CO release (Table 2). The $t_{1 / 2}$ of CO release decreases as a function of $E_{\text {red }}\left(\mathrm{Co}^{\mathrm{III}} / \mathrm{Co}^{\mathrm{I}}\right)$, matching the results obtained for the $t_{1 / 2}$ of aquation of the $\mathrm{Re}^{\mathrm{II}}$ CORM within CORM-biovectors 8-14. Our results

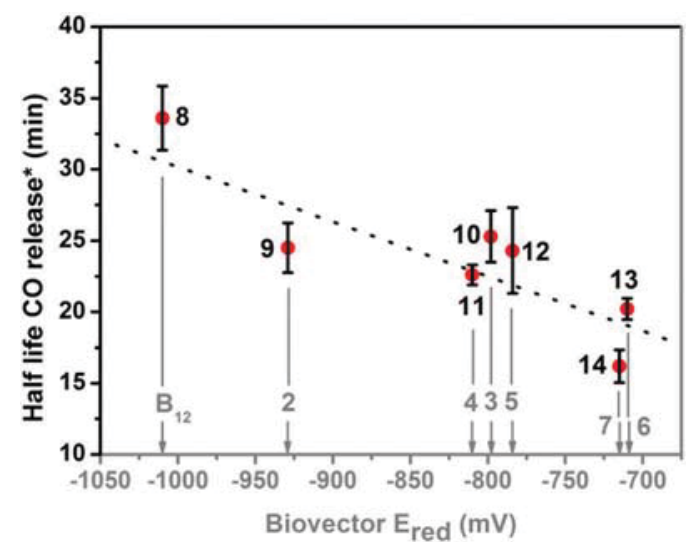

Fig. 2 Plot of $t_{1 / 2}(\mathrm{~min})$ of hyperchromic shift in the MbCO Soret band $\left(\lambda_{\max }=424 \mathrm{~nm}\right)$ of a $\mathrm{Mb}$ solution exposed to compounds 8-14 vs. reduction potential of Co'l' to Co' of the same species. * The $t_{1 / 2}$ of hyperchromic shift of the $424 \mathrm{~nm}$ soret band is taken as a direct measure of $t_{1 / 2}$ of $\mathrm{CO}$ release.

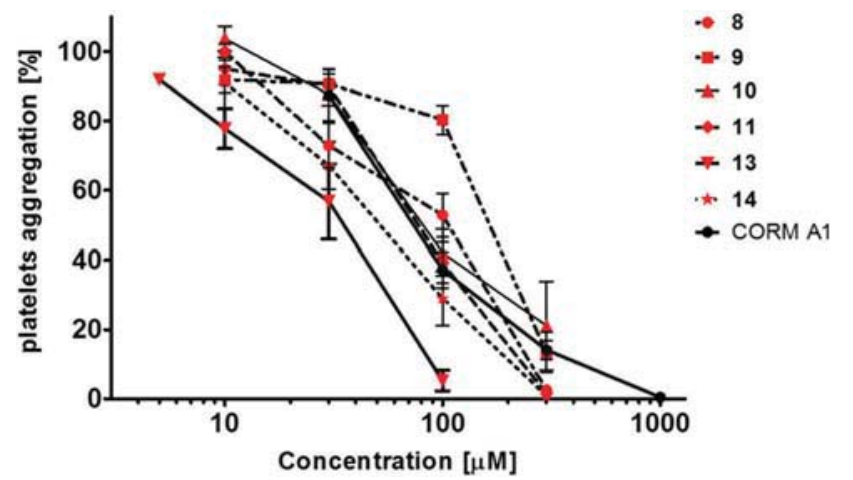

Fig. 3 Inhibition of platelet aggregation by $\mathrm{B}_{12}$-ReCORMs and CORM A1. Results presented as a mean \pm SEM ( $n=4-22)$. point to three defined areas of CO-release within the range of 15-35 min: a $t_{1 / 2}$ of CO release in a 30-35 min range for cobalamin derivatives with an $E_{\text {red }} \leq-1 \mathrm{~V}$; a $20-25 \mathrm{~min}$ range between -0.95 and $-0.75 \mathrm{~V}$; a $15-20$ min range for Co $E_{\text {red }}>-0.75 \mathrm{~V}$ (Fig. 2).

These results are important since the modulation of the $t_{1 / 2}$ of CO release allowed us to study the biological effects on the inhibition of platelet aggregation of various CO-releasing rates within a family of structurally similar CORM compounds in comparison with CORM A1 that has a $t_{1 / 2}$ of CO release of approximately $20 \mathrm{~min}^{16}$ As shown in Fig. 3 and Table 3, all $\mathrm{B}_{12}$-ReCORMs (compounds 8-14) inhibited platelet aggregation in the concentration range of 10 to $300 \mu \mathrm{M}$. In fact, the anti-aggregatory effects of $8\left(\mathrm{IC}_{50}=79.64 \pm 1.21\right), \mathbf{1 0}\left(\mathrm{IC}_{50}=\right.$ $87.64 \pm 1.13), 11\left(\mathrm{IC}_{50}=80.87 \pm 1.17\right)$ and $14\left(\mathrm{IC}_{50}=48.20 \pm\right.$ 1.21) were quite similar to each other and in the same range as observed for CORM A1 $\left(\mathrm{IC}_{50}=77.13 \pm 1.17\right) .{ }^{6,7}$ Only $\mathrm{B}_{12}$-CORMs $9\left(\mathrm{IC}_{50}=206.2 \pm 1.22\right)$ and $13\left(\mathrm{IC}_{50}=29.39 \pm 1.21\right)$ deviated significantly from these values (see Table 3). Compounds 8-11, 14 and CORM A1 inhibited platelet aggregation by more than $80 \%$ at $300 \mu \mathrm{M}$, while $\mathbf{1 3}$ achieved the same effect already at $100 \mu \mathrm{M}$. Accordingly, all the presented CORM-biovectors have anti-aggregatory effects relatively close to CORM A1. Only 13 displays a slightly more potent anti-platelet activity than CORM $\mathrm{A} 1$ and the other tested $\mathrm{B}_{12}$-ReCORMs. ${ }^{6-8}$

In summary, we have presented a series of $\mathrm{B}_{12}$-ReCORMs with tuneable $\mathrm{CO}$ releasing properties. These CORM-biovectors were synthesized by connecting a $\mathrm{Re}^{\mathrm{II}}$-dicarbonyl CORM and modified $\mathrm{B}_{12}$ derivatives through a cyanide bridge. In this proof-of-concept study it was demonstrated that alterations of the electronic properties at the $\mathrm{Co}^{\mathrm{III}}$ center of the $\mathrm{B}_{12}$-biovectors translate directly into variations of the $\mathrm{CO}$ release kinetics at the $\mathrm{Re}^{\mathrm{II}}$ metal ion. Although differentiation of the CO releasing kinetics between the different complexes is still relatively small, we demonstrated already that $\mathrm{B}_{12}$-ReCORMs displayed pronounced anti-platelet activity similar or even slightly higher than CORM A1, a compound that affords anti-platelet and antithrombotic activities in vivo without a hypotensive effect. ${ }^{7}$ These findings are encouraging for our future efforts to develop tuneable $\mathrm{B}_{12}$-ReCORMs with further optimized CO-releasing properties to achieve optimal anti-platelet effects for therapeutic applications.

This was supported by National Science Centre grant no. DEC-2013/08/M/MN7/01034 (SCH), the Swiss National Science Foundation Grant no. PP00P2_144700 (FZobi) and a fellowship of the Forschungskredit of the University of Zurich UZH to LP. A generous gift of vitamin $B_{12}$ was obtained from DSM Nutritional Products AG (Basel/Switzerland) and Prof. B. Jaun (retired ETH Zurich).

Table $3 \quad I C_{50}$ values for anti-aggregatory effects of $B_{12}$-ReCORMs and CORM A1

\begin{tabular}{|c|c|c|c|c|c|c|c|}
\hline COMP. & 8 & 9 & 10 & 11 & 13 & 14 & CORMA1 \\
\hline $\mathrm{IC}_{50} \pm \mathrm{SEM}$ & $79.64 \pm 1.21$ & $206.20 \pm 122$ & $87.64 \pm 1.13$ & $80.87 \pm 1.17$ & $29.39 \pm 1.21$ & $48.20 \pm 1.21$ & $77.13 \pm 1.17$ \\
\hline
\end{tabular}




\section{Notes and references}

1 R. Motterlini and L. E. Otterbein, Nat. Rev. Drug Discovery, 2010, 9, 728-743.

2 U. Schatzschneider, Br. J. Pharmacol., 2015, 172, 1638-1650.

3 S. Garcia-Gallego and G. J. L. Bernardes, Angew. Chem., Int. Ed., 2014, 53, 9712-9721.

4 S. H. Heinemann, T. Hoshi, M. Westerhausen and A. Schiller, Chem. Commun., 2014, 50, 3644-3660.

5 F. Zobi, Future Med. Chem., 2013, 5, 175-188.

6 S. Chlopicki, M. Lomnicka, A. Fedorowicz, E. Grochal, K. Kramkowski, A. Mogielnicki, W. Buczko and R. Motterlini, Naunyn-Schmiedeberg's Arch. Pharmacol., 2012, 385, 641-650.

7 K. Kramkowski, A. Leszczynska, A. Mogielnicki, S. Chlopicki, A. Fedorowicz, E. Grochal, B. Mann, T. Brzoska, T. Urano, R. Motterlini and W. Buczko, Arterioscler., Thromb., Vasc. Biol., 2012, 32, 2149-2157.

8 S. Chlopicki, R. Olszanecki, E. Marcinkiewicz, M. Lomnicka and R. Motterlini, Cardiovasc. Res., 2006, 71, 393-401.

9 H. B. Suliman, F. Zobi and C. A. Piantadosi, Antioxid. Redox Signaling, 2016, 24, 345-360.

10 F. Zobi, O. Blacque, R. A. Jacobs, M. C. Schaub and A. Y. Bogdanova, Dalton Trans., 2012, 41, 370-378.

11 F. Zobi, L. Quaroni, G. Santoro, T. Zlateva, O. Blacque, B. Sarafimov, M. C. Schaub and A. Y. Bogdanova, J. Med. Chem., 2013, 56, 6719-6731.

12 E. Kottelat, A. Ruggi and F. Zobi, Dalton Trans., 2016, 45, 6920-6927.

13 M. Sonnay, T. Fox, O. Blacque and F. Zelder, Chem. Sci., 2016, 7, 3836-3842.

14 K. Zhou, R. M. Oetterli, H. Brandl, F. E. Lyatuu, W. Buckel and F. Zelder, ChemBioChem, 2012, 13, 2052-2055.
15 K. Zhou and F. Zelder, Angew. Chem., Int. Ed., 2010, 49, 5178-5180.

16 R. Motterlini, P. Sawle, S. Bains, J. Hammad, R. Alberto, R. Foresti and C. J. Green, FASEB J., 2005, 19, 284-286.

17 F. Zobi, L. Kromer, B. Spingler and R. Alberto, Inorg. Chem., 2009, 48, 8965-8970.

18 A. K. Petrus, T. J. Fairchild and R. P. Doyle, Angew. Chem., Int. Ed., 2009, 48, 1022-1028.

19 F. Zelder, Chem. Commun., 2015, 51, 14004-14017.

20 J. Rossier, D. Hauser, E. Kottelat, B. Rothen-Rutishauser and F. Zobi, Dalton Trans., 2017, 46, 2159-2164.

21 K. L. Brown, S. F. Cheng, X. Zou, J. D. Zubkowski, E. J. Valente, L. Knapton and H. M. Marques, Inorg. Chem., 1997, 36, 3666-3675.

22 S. M. Chemaly, K. L. Brown, M. A. Fernandes, O. Q. Munro, C. Grimmer and H. M. Marques, Inorg. Chem., 2011, 50, 8700-8718.

23 S. M. Chemaly, M. Florczak, H. Dirr and H. M. Marques, Inorg. Chem., 2011, 50, 8719-8727.

24 K. ó Proinsias, M. Giedyk and D. Gryko, Chem. Soc. Rev., 2013, 42, 6605-6619.

25 F. Wagner, Annu. Rev. Biochem., 1966, 35, 405-434.

26 R. M. Oetterli, L. Prieto, B. Spingler and F. Zelder, Org. Lett., 2013, 15, 4630-4633.

27 L. Prieto, M. Neuburger, B. Spingler and F. Zelder, Org. Lett., 2016, 18, 5292-5295.

28 R. Bonnett, J. R. Cannon, V. M. Clark, A. W. Johnson, L. F. J. Parker, E. L. Smith and A. Todd, J. Chem. Soc., 1957, 1158-1168.

29 S. Kunze, F. Zobi, P. Kurz, B. Spingler and R. Alberto, Angew. Chem., Int. Ed., 2004, 43, 5025-5029. 